\title{
Mechanical Ventilation Outcomes at the NICU at EL-Zahraa University Hospital
}

\author{
Aya Abdelkader Othman ${ }^{1}$, Zeinab Farag Oshaib ${ }^{2}$, Marwa El-Hady Abd El Moneim ${ }^{3}$ \\ ${ }^{1}$ Bachelor of Medicine and Surgery, Mansoura University, Mansoura, Egypt \\ ${ }^{2}$ Pediatrics and Neonataology Department, Faculty of Medicine for Girls, Al-Azhar University, Cairo, Egypt \\ ${ }^{3}$ Pediatric and Neonataology Department, Al Zahraa University Hospital, Faculty of Medicine for Girls, Al-Azhar University, \\ Cairo, Egypt \\ Email: *ayaalkosier@gmail.com
}

How to cite this paper: Othman, A.A., Oshaib, Z.F. and El Moneim, M.E.-H.A. (2020) Mechanical Ventilation Outcomes at the NICU at EL-Zahraa University Hospital. Open Journal of Pediatrics, 10, 732-743. https://doi.org/10.4236/ojped.2020.104074

Received: July 16, 2020

Accepted: December 21, 2020

Published: December 24, 2020

Copyright $\odot 2020$ by author(s) and Scientific Research Publishing Inc. This work is licensed under the Creative Commons Attribution International License (CC BY 4.0).

http://creativecommons.org/licenses/by/4.0/

\begin{abstract}
Background: Mechanical ventilation (MV) is one of the most common therapies in the neonatal Intensive Care Unit (NICU) and is associated with increased morbidity and mortality. MV is a complex and highly specialized area in neonatology that has several complications related to different modes, techniques, and devices. Aim of the Study: To detect the causes of morbidity and mortality in mechanically ventilated neonates and to correlate the neonatal morbidity and mortality with gestational age, birth weight and duration of MV. Patients and Methods: This prospective observation analytical study was carried out on 110 neonates who were admitted to NICU at Al-Zahraa university hospital on MV during the period from March 2019 to March 2020. All neonates were followed up till the time of discharge with record of any complications during mechanical ventilation. Detailed medical history, examination to detect indication of MV and laboratory, radiological investigations were recorded. As regard the general characterization of studied neonates, $64(58.2 \%)$ were males while the rest 46 (41.8\%) were females, 50 (45.4\%) were full term (37 - $42 \mathrm{wks}), 42$ (38.18\%) were early preterm (28 - 33 wks), 18 (16.3\%) were late preterm ( $34-42$ wks). Results: Among (110 mechanically ventilated neonates, $58.2 \%$ were males, $41.8 \%$ were females. The most common indication for MV in the studied cases was respiratory distress syndrome (RDS) in 30\% neonates. Ventilator associated pnemonia and Devices associated infection were the most common complications related to MV (19.1\% and $11.8 \%$ respectively). While septic shock and multiorgan failure were the most common complications related to the underlying disease (24\%). There is a significant negative association between gestational age, birth weight and mortality in mechanically ventilated neonates. the overall recovery was $59.1 \%$ among studied neonates. Conclusion: Respiratory dis-
\end{abstract}


orders were the commonest indication of MV in NICU mostly RDS. Ventilator associated pneumonia and devices associated infection are common complications. Preterm and low birth weight neonates are vulnerable group for need of mechanical ventilation.

\section{Keywords}

Mechanical Ventilation, Respiratory Distress Syndrome, VAP

\section{Introduction}

Mechanical ventilation may be defined as the movement of gas into and out of the lungs by an external source connected directly to the patient by way of a tracheostomy or an endotracheal tube [1].

Advances in perinatal and neonatal care have significantly reduced neonatal morbidity and mortality rates. Outcome in sick infants has improved significantly, mostly due to more effective newborn intensive care and aggressive respiratory and cardiovascular support using mechanical ventilation in neonatal Intensive Care Units (NICU) [2].

A significant proportion of neonates admitted to NICU requires mechanical ventilation. Mechanical ventilation is a proper intervention to increase the survival rate of the neonates and one of the essential components of NICU. However, mechanically ventilated neonates have a high fatality. Variation in the mortality among mechanically ventilated neonates has been attributed to more biomedical technological advancements in the developed countries. Various studies in developing countries have shown a mortality rate in the range of $40 \%-60 \%$ [3].

The need for mechanical ventilation relies on various elements, like primary disease, gestational age, birth weight and related clinical conditions. In order to improve the survival in mechanically ventilated neonates, identification of prognostic factors and their treatment is mandatory [4].

Despite that MV provide a life-saving modality in NICU its use is associated with high risk mortality [5].

Various studies in developing countries have shown a mortality rate in the range of $40 \%-60 \%$ [3] about indications and outcome in Neonatal mechanical ventilation. A Total of 300 ventilated neonates were included in the study. They reported that among 300 ventilated neonates, respiratory distress syndrome (31.1\%), sepsis $(22.7 \%)$, and birth asphyxia (18\%) were the most common indications for ventilation which is consistent with our results. In the study of Torres-Castro et al. (2016), they reported that the most common indication for MV was RDS which was presented in 35 (66\%) neonates. These results were consistent with our results. In the study of Monsef et al. (2019), they reported that RDS (58.9\%) was the most common indication for mechanical ventilation. Which is also consistent with our results [3].

Regarding outcome of mechanically ventilated neonates in our study, the 
overall recovery in mechanically ventilated neonates was (59.1\%). Our results are similar to Iqbal et al. (2015) and Sangeeta et al. (2009) with recovery rate 57\%, 54\% respectively. Our results more than of Hossain et al. (2009) and Mathur et al. (2005) with recovery rates $30 \%$ and $26 \%$ respectively, and less than those of Prabha et al. (2014) with 75\% recovery [2] [3] [6] [7] [8].

\section{Aim of the Study}

To detect the causes of morbidity and mortality in mechanically ventilated neonates and to correlate the neonatal morbidity and mortality with gestational age, birth weight and duration of MV.

\section{Patients and Methods}

\subsection{Patients}

This prospective observation analytical study was carried on all neonates admitted to our (NICU) at El-Zahraa University Hospital who need mechanical ventilation during the period from March 2019 to March 2020. All neonates were followed up till the time of discharge with record of any complications during mechanical ventilation.

The study was approved by the local research ethics committee of the pediatric department at Al-Azhar University for girls and a written informed consent was taken from caregivers of all participants after proper explanation of the study.

\section{Inclusion criteria:}

- Neonates within neonatal age range (0 - 28) days after birth.

- Gestational age: Both preterm and full term neonates.

- Sex: both male and female.

- Delivered either by normal vaginal delivery or ceasarean section.

- Sick neonates admitted to our NICU who need conventional mechanical ventilation.

\section{Exclusion criteria:}

- Neonates who were beyond neonatal period (more than 28 days).

- Neonates with congenital malformations.

\subsection{Methods}

During the period of the study, All included neonates were subjected to complete history taking, maternal antenatal history including maternal age, risk factor, maternal infection, maternal drug intake, exposure to radiation, antepartum hemorrahage, maternal follow up. Natal history including: Mode of delivery, place of delivery, complicated or not, outcome of pregnancy gestational age, birth weight, PROM, signs of chorioamnionitis (intra-partum fever or offensive vaginal discharge). post-natal history including: Post-natal age, apgar score at one minute and five minutes, type of resuscitation needed, color (cyanosis, pallor, jaundice), RD, convulsions. Detailed clinical examination including: 1) general examination including assessment gestational age by modified Ballard score, 
anthropometric measures, vital signs assessment, general conditions, activity, color of the baby. 2) detaliled systemic examination.

Initial, routine radiological, laboratory investigations as recommended by our local NICU protocol and guidelines including complete blood count, C-reactive protein, arterial blood gases, kidney function, liver function, electrolytes, chest $\mathrm{X}$-ray, blood culture) and any other investigation when ordered in relation to specific health problem.

\subsection{Statistical Analysis}

Data were collected, revised, coded and entered to the Statistical Package for Social Science (IBM SPSS) version 20. The quantitative data were presented as mean, standard deviations and ranges while qualitative variables were presented as number and percentages. The comparison between groups was done using independent $t$ test, Chi-square test and/or Fisher exact test when the expected count in any cell found less than 5. The comparison between more than two groups regarding quantitative data and parametric distribution was done by using One Way ANOVA test while with non-parametric distribution was done by using Kruskall-Wallis test. Spearman correlation coefficients were used to assess the correlation between two quantitative parameters in the same group. The confidence interval was set to $95 \%$ and the margin of error accepted was set to $5 \%$. So, the P-value was considered significant as the following: P-value $>0.05$ : Non significant (NS), P-value < 0.05: Significant (S) and P-value < 0.01: Highly significant (HS).

\section{Results}

Among our studied neonates $64(58.2 \%)$ were males and $46(41.8 \%)$ were females. $45.4 \%$ were full term while $16.3 \%$ and $38.1 \%$ were late and early preterm respectively. $58.2 \%$ were low birth weight (less than $2.5 \mathrm{~kg}$ ). $70 \%$ were born via CS. $60 \%$ had maternal risk factors (hypertension, PROM, DM), as demonstrated in Table 1.

The most common indication for MV in the studied cases was RDS 30\% followed by congenital pneumonia and sepsis. $16.4 \%$ of each and apnea in $9 \%$ of cases. As regard the outcome, $59.1 \%$ were survived while $40.9 \%$ died as shown in Table 2 .

$41.8 \%$ of the studied neonates developed complications related to MV. The most common was VAP in $21 \%$ of cases followed by device associated blood born infection in $13.3 \%$ of cases. $56.7 \%$ of the studied neonates developed complications related to the underlying disease not related to MV. The most common complication was septic shock, Multi organ failure (MOF) is $21.8 \%$ of cases followed by DIC $17.2 \%$ and NEC is $10.9 \%$ of cases as shown in Table 3 .

The neonates who had lower gestational age and lower birth weight more suscebtible to mortality than the higher ones as demonstrated in Table 4.

Ventilator associated pneumonia, DIC and NEC were significantly higher incidence among the died neonates as demonstrated in Tables 5-9. 
Table 1. General characterization of studied neonates.

\begin{tabular}{ccc}
\hline Neonatal demographic characteristics & $\mathbf{n}=110$ & $\%$ \\
\hline Sex & 64 & 58.2 \\
Male & 46 & 41.8 \\
Female & & \\
Gestational age (weeks) & 42 & 38.18 \\
Early preterm; (28 - 336/7 wks) & 18 & 16.3 \\
Late preterm; (34 - 366/7 wks) & 50 & 45.4 \\
Full term; (37 - 42 wks) & & 3.6 \\
Birth weight (g) & 4 & 30 \\
Extremely Low birth weight; (less than $1000 \mathrm{gm})$ & 33 & 24.5 \\
Very low birth weight; (1000 gm to less than $1500 \mathrm{gm})$ & 27 & 41.8 \\
Low birth weight; (1500 gm to less than $2500 \mathrm{gm})$ & 46 & \\
Normal birth weight; (2500 gm to less than $4000 \mathrm{gm})$ & &
\end{tabular}

Table 2. Maternal general characterization and Mode of birth of enrolled neonates.

\begin{tabular}{|c|c|c|}
\hline Maternal general characterization & $\mathrm{n}=110$ & $\%$ \\
\hline \multicolumn{3}{|l|}{ Maternal age } \\
\hline Appropriate maternal Age; [20 - 35 years old] & 60 & 54.5 \\
\hline Non appropriate-Low maternal age; [less than 20 ys] & 30 & 27.27 \\
\hline Non appropriate-high maternal age; [more than $35 \mathrm{ys}$ ] & 20 & 18.8 \\
\hline \multicolumn{3}{|l|}{ Maternal risk factors } \\
\hline Hypertension & 25 & 22.7 \\
\hline Diabetes mellitus & 22 & 20 \\
\hline PROM & 19 & 17.3 \\
\hline No reported risk factor & 44 & 40 \\
\hline \multicolumn{3}{|l|}{ Mode of delivery } \\
\hline NVD & 40 & 36.3 \\
\hline CS & 70 & 63.7 \\
\hline
\end{tabular}

CS, caesarean section; NVD, normal vaginal delivery; PROM, premature rupture of membrane.

Table 3. Indication of MV and outcome of the studied neonates.

\begin{tabular}{ccc}
\hline \multicolumn{1}{c}{ Indication of $\mathrm{MV}$} & & \\
Diseases & $\mathrm{n}=110$ & $\%$ \\
\hline $\begin{array}{c}\text { Respiratory distress syndrome } \\
\text { Congenital pneumonia }\end{array}$ & 33 & 30 \\
Sepsis & 18 & 16.4 \\
Apnea & 18 & 9 \\
Perinatal asphyxia & 10 & 7.2 \\
Congenital Heart diseases & 8 & 6.4 \\
Persistent pulmonary hypertension & 7 & 5.5 \\
Air-leak syndrome & 6 & 5.5 \\
Meconium aspiration syndrome & 6 & 3.6
\end{tabular}


Table 4. Complications related to mechanical ventilation among enrolled neonates $(\mathrm{n}=$ 110).

\begin{tabular}{ccc}
\hline Complications related to mechanical ventilation & $\mathrm{N}=46$ & $41.8 \%$ \\
\hline VAP & 21 & 19.1 \\
Devices associated blood born infection & 13 & 11.8 \\
BPD & 5 & 4.5 \\
Air-leak syndromes & 4 & 3.6 \\
Extubation failure & 3 & 2.7 \\
\hline
\end{tabular}

BPD: broncho pulmonary dysplasia; VAP: ventilator associated pneumonia.

Table 5. Complications related to disease pattern among studied neonates $(n=110)$.

\begin{tabular}{ccc}
\hline Complication related to disease pattern & $\mathrm{N}=64$ & $56.7 \%$ \\
\hline Septic shock, MOF & 24 & 21.8 \\
DIC & 19 & 17.2 \\
NEC & 12 & 10.9 \\
Acute kidney injury & 6 & 5.4 \\
Pulmonary hemorrhage & 3 & 2.7 \\
\hline
\end{tabular}

MOF: multi-organ failure; DIC: disseminated intravascular coaglopathies; NEC: necrotizing enterocolitis.

Table 6. Comparison between survived and non survived neonates according to neonatal baseline characteristics.

\begin{tabular}{|c|c|c|c|}
\hline \multirow[b]{2}{*}{ Parameters } & \multicolumn{2}{|c|}{ Outcome } & \multirow[b]{2}{*}{$\mathrm{P}$-value } \\
\hline & $\begin{array}{l}\text { Survived neonates } \\
\qquad \mathrm{n}=65\end{array}$ & $\begin{array}{l}\text { Nonsurvived neonates } \\
\qquad \mathrm{n}=45\end{array}$ & \\
\hline \multicolumn{4}{|c|}{ Sex; n (\%) } \\
\hline Male & $35(53.8)$ & $29(64.4)$ & \multirow{2}{*}{0.268} \\
\hline Female & $30(46.2)$ & $16(35.6)$ & \\
\hline \multicolumn{4}{|c|}{ Gestational age; wks* } \\
\hline Median (IQR) & $35(30.2-39.8)$ & $31(28-38)$ & \multirow{2}{*}{$<0.0001^{*}$} \\
\hline Min-Max & $29-42$ & $28-39$ & \\
\hline \multicolumn{4}{|c|}{ Gestational age (weeks); n (\%) } \\
\hline Earlypre term [28 - 326/7 wks] & $14(21.5)$ & $28(62.2)$ & \multirow{3}{*}{$<0.0001^{\star}$} \\
\hline Latepre term $[33-306 / 7$ wks] & $14(21.5)$ & $4(8.8)$ & \\
\hline Full term [37 - $42 \mathrm{wks}]$ & $37(57)$ & $13(28.9)$ & \\
\hline \multicolumn{4}{|c|}{ Birth weight; $\mathrm{Kg}^{*}$} \\
\hline Median (IQR) & $2.5(1.42-3.79)$ & $1.45(1.05-3.5)$ & \multirow{2}{*}{$0.005^{\star}$} \\
\hline Min-Max & $1350-3950$ & $950-3900$ & \\
\hline \multicolumn{4}{|c|}{ Birth weight categories; n (\%) } \\
\hline $\begin{array}{l}\text { Extremely Low birth weight } \\
\text { (less than } 1000 \text { gm) }\end{array}$ & $2(3.02)$ & $2(4.44)$ & \multirow{4}{*}{$0.012^{*}$} \\
\hline $\begin{array}{l}\text { Very low birth weight } \\
\text { [1000 gm to less than } 1500 \mathrm{gm}]\end{array}$ & $14(21.5)$ & $20(44.4)$ & \\
\hline $\begin{array}{l}\text { Low birth weight } \\
\text { [1500 gm to less than } 2500 \mathrm{gm}]\end{array}$ & $14(21.5)$ & $12(27.7)$ & \\
\hline $\begin{array}{c}\text { Normal birth weight } \\
\text { [2500 gm to less than } 4000 \mathrm{gm}]\end{array}$ & $36(54)$ & $11(24.5)$ & \\
\hline
\end{tabular}

Statistical analysis: ${ }^{\star}$ Significant at $\mathrm{P}<0.05$. 
Table 7. Comparison between survived and non survived neonates according to maternal general characteristics.

\begin{tabular}{cccc}
\hline $\begin{array}{c}\text { Maternal general } \\
\text { characterization }\end{array}$ & $\begin{array}{c}\text { Survived neonates } \\
\mathbf{N}=\mathbf{6 5}\end{array}$ & $\begin{array}{c}\text { Non survived neonates } \\
\mathbf{N}=\mathbf{4 5}\end{array}$ & p-value \\
\hline & Maternal Age; years & & \\
Median (IQR) & $26(19-32)$ & $28(16-38)$ & $\mathbf{0 . 9 6 5}$ \\
Min-Max & $18-38$ & $16-40$ & \\
& Maternal risk factors & & \\
Hypertension & $15(23.1)$ & $11(24.4)$ & $\mathbf{0 . 1 6 7}$ \\
Diabetes & $11(10.9)$ & $11(24.4)$ & \\
PROM & $9(13.8)$ & $11(24.4)$ & \\
No reported risk factor & $30(46.2)$ & $12(26.8)$ & \\
& Mode of delivery; $\mathrm{n}(\%)$ & & $\mathbf{0 . 3 3 8}$ \\
NVD & $23(35.4)$ & $17(37.7)$ & \\
CS & 42 (ó4.6) & $28(62.3)$ & \\
\hline
\end{tabular}

NVD: normal vaginal delivery; CS: caesarean section; IQR: interquartile ration; PROM: premature rupture of membrane.

Table 8. Comparison between survived and non survived neonates regarding complication of mechanical ventilation and outcome.

\begin{tabular}{cccc}
\hline & \multicolumn{2}{c}{ Complications } \\
& $\begin{array}{c}\text { Survived Neonates } \\
\mathbf{n}=\mathbf{6 5}\end{array}$ & $\begin{array}{c}\text { Nonsurvived Neonates } \\
\text { Complications related to }\end{array}$ & $\mathbf{n}=\mathbf{4 5}$ \\
VAP & $8(12.3 \%)$ & $13(28.9 \%)$ & $\mathbf{0 . 0 3 4}$ \\
Devices anical ventilation; $\mathbf{n}=46$ & \\
BPD & $6(9.2 \%)$ & $7(15.6 \%)$ & 0.333 \\
Air leak syndromes & $2(3.1 \%)$ & $3(6.7 \%)$ & 0.388 \\
Extubation Failure & $2(3.1 \%)$ & $2(4.4 \%)$ & 0.723 \\
\hline
\end{tabular}

BPD: broncho pulmonary dysplasia; VAP: ventilator associated pneumonia.

Table 9. Comparison between survived and non survived neonates regarding complication related to Disease and outcome.

\begin{tabular}{cccc}
\hline & \multicolumn{2}{c}{ Complications } \\
\cline { 2 - 3 } & $\begin{array}{c}\text { Survived Neonates } \\
\mathbf{n}=65\end{array}$ & $\begin{array}{c}\text { Non survived Neonates } \\
\mathbf{n}=45\end{array}$ & p-value \\
Complications related to mechanical ventilation; $\mathbf{n}=64$ \\
Septic shock \& MOF & $11(24.4 \%)$ & $13(20 \%)$ & 0.681 \\
DIC & $3(6.7 \%)$ & $16(24.6 \%)$ & 0.014 \\
NEC & $1(2.2 \%)$ & $11(16.9 \%)$ & 0.015 \\
Acute kidney injury & $1(2.2 \%)$ & $5(7.7 \%)$ & 0.214 \\
Pulmonary hemorrhage & $0(0 \%)$ & $3(6.7 \%)$ & 0.340 \\
\hline
\end{tabular}




\section{Discussion}

As regard the general characterization of studied neonates, 110 neonates included in our study 64 (58.2\%) were predominance with high male sex affection while the rest $46(41.8 \%)$ were females Our findings are in agreement with Hossain et al. (2009) who included 51 very sick neonates who required mechanical ventilation. among the ventilated neonates $58.8 \%$ were males and $41.2 \%$ were females and male female ratio was 1.42:1 [7].

Our findings are lower than the results of study done by Sultana et al. (2020) who found predominant male gender among ventilated neonates with $69.8 \%$ male and $30.2 \%$ female in agreement with our results (male predominance) [9].

This male gender preference could be explained by the higher incidence of respiratory distress syndrome in males than females due to the effect of testosterone on surfactant production (Baseer et al., 2020) [10].

On the other hand, Torres-castro et al. (2016) found that females were 51\% while males $49 \%$ among ventilated neonates in their study. This contradiction could be explained by difference in methodological techniques, inclusion and exclusion criteria of those studies or difference in the study sample [11].

Regarding gestational age distribution, full term neonates were 50 (45.4\%), early preterm $18(16.3 \%)$, and late preterm $42(38.18 \%)$ in accordance to our findings, Trividi et al. (2009), found that out of mechanically ventilated studied neonates (16\%) were early preterm, (30\%) were late preterm, $(54 \%)$ were full term. In disagreement with our results, the results of the study done by Sultana et al. (2020) who found that out of mechanically ventilated studied neonates (20.8\%) were full term (79.2\%) were preterm and Torres-castro et al. (2016), out of mechanically ventilated studied neonates only (13\%) were full term and (40\%) were early preterm, (47\%) were late preterm [11] [12].

These findings reflect the negative association between gestational age and the need for mechanical ventilation. This could be explained by immature lung and poor production of surfactant that increase the risk for RDS and BPD among those with lower gestational age [13].

Regarding birth weight categorization among our studied mechanically ventilated neonates, 46 (41.8\%) were Normal birth weight, 27 (24.5\%) were Low birth weight, $33(30 \%)$, were very low birth weight and 4 (3.6\%) were extremely low birth weight. These findings indicate that the lower birth weight the more susceptibility to require mechanical ventilation. This could be explained by the high rate of preterm infants included in our study.

And this is in agreement with Sultana et al. (2020) who found that among mechanically ventilated neonates $20.8 \%$ were normal birth weight and $79.2 \%$ were low birth weight.

And in agreement also with Torres-Castro et al. (2016) who found 21\% were normal birth weight, $79 \%$ low birth weight among mechanically ventilated neonates [9] [11].

As regarding disease pattern of mechanically ventilated neonates. The most 
common indication for mechanical ventilation in the studied cases was respiratory distress syndrome 33 (30\%) neonates, congenital pneumonia 18 (16.4\%), sepsis $18(16.4 \%)$, apnea $10(9 \%)$, perinatal asphyxia $8(7.2 \%)$, congenital Heart diseases 7 (6.4\%), persistent pulmonary hypertension 7 (5.5\%), air-leak syndrome $6(5.5 \%)$, and the least presentation was meconium aspiration syndrome $4(3.6 \%)$.

In the study by Iqbal et al. (2015) about indications and outcome in Neonatal mechanical ventilation. A Total of 300 ventilated neonates were included in the study. They reported that, Among 300 ventilated neonates. Respiratory distress syndrome $(31.1 \%)$, sepsis $(22.7 \%)$, and birth asphyxia (18\%) were the most common indications for ventilation which is consistent with our results [3].

Also, Sultana et al. (2019) study assessed the outcome of Neonates Requiring Mechanical Ventilation. They found that commonest initiation of mechanical ventilation was refractory apnea (35.8\%) followed by respiratory distress syndrome $(20.8 \%)$, congenital pneumonia (18.9\%), perinatal asphyxia (15.1\%), meconium aspiration syndrome (3.8\%), TTN (1.9\%) and meningitis (3.8\%). Which is also consistent with our results [9].

Similar to our findings, Torres-Castro et al. (2016) and Monsef et al. (2019) reported that the most common indication for mechanical ventilation in NICU was respiratory distress syndrome that represent (66\%) and (58.9)\% of mechanically ventilated neonates respectively [11] [14].

As regard complication of mechanical ventilation and disease related complications among the studied neonates. Complications related to mechanical ventilation occurred in $(41.8 \%)$ of studied neonates. Ventilator associated pneumonia occurred in (19.1\%) patients, devices associated blood born infection (11.8\%). broncho pulmonary dysplasia (4.5\%), Air-leak syndromes (3.6\%), extubation failure (2.7\%).

In the study of Sultana et al. (2019), device associated sepsis (67.9\%) was the most common complication during mechanical ventilation followed by tube block (52.8\%) and ventilator associated pneumonia (26.4\%) [9].

In the study of Torres-Castro et al. (2016), to detect pulmonary complications associated with mechanical ventilation in neonates. The most common pulmonary complications were atelectasis (35\%), pneumonia (27.5\%), pneumothorax (15\%), bronchopulmonary dysplasia (15\%), pneumomediastinum (15\%) and pulmonary hemorrhage $(2.5 \%)$. Atelectasis is the most common pulmonary complication in neonatal patients undergoing mechanical ventilation [11].

In our study complications related to disease pattern occurred in 64 (58.2\%) of patients. Septic shock \& MOF occurred in (21.8\%), DIC (17.27\%), NEC (10.9\%), Acute kidney injury (5.4\%) and Pulmonary hemorrhage 3 (2.7\%).

In the study of Iqbal et al. (2015), the disease related complication in mechanically ventilated neonates were septic shock, hypoglycemia that were significantly associated with high mortality [3].

In the study of Sultana et al. (2019), shock (64\%) was the commonest 
co-morbidity followed by dyselectroltemia (52.8\%), sepsis (35.8\%) and DIC (28.3\%). Hospital acquired sepsis, shock and DIC were associated with mortality $(\mathrm{p}<0.05)$. Shock was found independent predictor of mortality $(\mathrm{p}=0.001)$ [9].

Mortality among sick neonates in NICU is high, but mortality among mechanically ventilated neonates and newborn neonates referred for ventilation is even higher [15].

Regarding outcome of mechanically ventilated neonates in our study, the overall recovery in mechanically ventilated neonates was (59.1\%). Our results are similar to Iqbal et al. (2015) and Sangeeta et al. (2009) with recovery rate $57 \%, 54 \%$ respectively. Our results more than of Hossain et al. (2009) and Mathur et al. (2005) with recovery rates $30 \%$ and $26 \%$ respectively, and less than those of Prabha et al. (2014) with 75\% recovery [2] [3] [7].

These differences in recovery rates due to differences in underlying diseases, severity of prematurity and care quality. Technological advancements in developed countries may also be additional factors [14].

Regarding various variables characterization of studied neonates in relation to outcome. There was a statistically significant association between lower gestational age, lower birth weight and non survival in mechanically ventilated neonates with p-value $(<0.001)$ and $(0.012)$ respectively.

Similar to our findings, Sultana et al. (2019) and Hussein et al. (2009) found that mean gestational age and mean birth weight, initial $\mathrm{PH}$ were significantly higher in survived than non survived neonates with p-value $<0.05$ [7] [9].

Regarding complications of studied neonates related to MV, ventilator associated pneumonia was significantly higher in non survived mechanically ventilated neonates, with p-value 0.034 . Regarding complications of studied neonates related to pattern of disease, NEC, DIC, Respiratory acidosis had significant difference between survived and non survived mechanically ventilated neonates, with p-value $(0.014,0.015,<0.001)$ respectively .

In the study of Iqbal et al. (2015), they concluded that, among the numerous commonly available variables, birth weight $<2500$ g, gestation $<34$ weeks, initial arterial $\mathrm{pH}<7.1$, VAP, pulmonary hemorrhage, apnea with. were significant predictors of mortality in ventilated neonates. Which is consistent with our results, with p-value $(0.03,0.002,0.0022,<0.0001)$ respectively [3].

In the study of Hossain et al. (2009), there was a significant relationship between outcome of mechanical ventilation and gestational age, neonatal birth weight, and initial $\mathrm{pH}$ with $\mathrm{p}$-value $(0,006,0.04,0.04)$ respectively $(\mathrm{P}<0.05)$, which is in agreement with our results [7].

\section{Limitations}

- Our study did not focus on the proportion of patients receiving noninvasive ventilation/CPAP who subsequently needed intubation and mechanical ventilation.

- Small number of included neonates in our study. 


\section{Conclusions}

1) The commonest indicator of mechanical ventilation in NICU was severe RDS.

2) Ventilator associated pneumonia and device blood-borne infection are the most common complications related to mechanical ventilation.

3) Preterms and low birth weight are the vulnerable groups who require mechanical ventilation.

4) There is significant inverse association between gestational age, birth weight and mortality in mechanically ventilated neonates.

5) VAP is associated with increase the mortality in mechanically ventilated neonates.

6) Respiratory acidosis and high pco2 level were associated with higher mortality in MV neonates.

\section{Recommendations}

1) Greater efforts should be put in to decrease the burden of premature deliveries to decrease the frequency of NICU admission and the need for MV.

2) There should be improvement in the strategies to prevent ventilator associated pneumonia to decrease the mortality in mechanically ventilated neonates.

3) The infection control strategies should be improved to prevent and decrease the rate of device associated blood-borne infection in mechanically ventilated neonates.

Medical staff awareness of complications and morbidities related to mechanical ventilation should be increased.

\section{Conflicts of Interest}

The authors declare no conflicts of interest regarding the publication of this paper.

\section{References}

[1] Ali, M.B., Maruf, A.A. and Rashid, M.M. (2018) Pattern and Outcome of Admissions in a Neonatal High Dependency Unit of a Medical College Hospital in Khulna, Bangladesh. Mediscope, 5, 1-7. https://doi.org/10.3329/mediscope.v5i2.37141.

[2] Prabha, P.C.N., Tresa George, R. and Francis, F. (2014) Profile and Outcome of Neonates Requiring Ventilation: The Kerala Experience. Current Pediatric Research, 18, 57-62.

[3] Iqbal, Q., Younus, M.M., Ahmed, A., Ahmad, I., Iqbal, J., Charoo, B.A. and Ali, S.W. (2015) Neonatal Mechanical Ventilation: Indications and Outcome. Indian Journal of Critical Care Medicine, 19, 23-27. https://doi.org/10.4103/0972-5229.164800

[4] Sharma, R. and Baheti, S. (2017) Outcome of Neonatal Ventilation: A Prospective and Cross-Sectional Study in Tertiary Care Centre. International Journal of Contemporary Pediatrics, 4, 1820-1826.

https://doi.org/10.18203/2349-3291.ijcp20173793 
[5] Sangeeta, S.T., Rajesh, K.C. and Anurakti, S. (2009) Study of Early Predictors of Fatality in Mechanically Ventilated Neonates in NICU. Online Journal of Health and Allied Sciences, 8, 3-9.

[6] Chatburn, R.L. (2003) Fundamentals of Mechanical Ventilation. Mandu Press Ltd., Cleveland Heights, 114-123.

[7] Sultana, S.N., Khan, M.M., Islam, M.T., Afroze, S., Jahan, I., Dey, S.K., Mannan, M.A. and Shahidullah, M. (2019) Clinical Profile and Outcome of Neonates Requiring Mechanical Ventilation. Birth, 37, 20-28.

[8] Hossain, M.M., Mahfuza, S., Abdullah, M.A., Hassan, M.N. and Sahidullah, M. (2009) Predictors of Mortality in Ventilated Neonates in Intensive Care Unit. Bangladesh Journal of Child Health, 33, 77-82. https://doi.org/10.3329/bjch.v33i3.5687

[9] Mathur, N.B., Garg, P. and Mishra, T.K. (2005) Predictors of Fatality in Neonates Requiring Mechanical Ventilation. Indian Pediatrics, 42, 645-651.

[10] Torres-Castro, C., Valle-Leal, J., Martínez-Limón, A.J., Lastra-Jiménez, Z. and Delgado-Bojórquez, L.C. (2016) Pulmonary Complications Associated with Mechanical Ventilation in Neonates. Boletín Médico Del Hospital Infantil de México (English Edition), 73, 318-324. https://doi.org/10.1016/j.bmhime.2016.08.001.

[11] Baseer, K.A., Mohamed, M. and Abd-Elmawgood, E.A. (2020) Risk Factors of Respiratory Diseases among Neonates in Neonatal Intensive Care Unit of Qena University Hospital, Egypt. Annals of Global Health, 86, 22.

https://doi.org/10.5334/aogh.2739

[12] Trivedi, S.S., Chudasama, R.K. and Srivastava, A. (2009) Study of Early Predictors of Fatality in Mechanically Ventilated Neonates in NICU. The Online Journal of Health and Allied Sciences, 8, 9.

[13] Sant'Anna, G.M. and Keszler, M. (2012) Developing a Neonatal Unit Ventilation Protocol for the Preterm Baby. Early Human Development, 88, 925-929. https://doi.org/10.1016/j.earlhumdev.2012.09.010

[14] Monsef, A.R., Eghbalian, F., Sabzehei, M.K. and Khanlarzade, E. (2019) Evaluating the Short-Term Outcome of Mechanically Ventilated Neonates Admitted to the Neonatal Intensive Care Unit of Besat Hospital, Hamadan, Iran. International Journal of Pediatrics, 7, 10029-10034.

[15] Arafa, M.A. and Alshehri, M.A. (2003) Predictors of Neonatal Mortality in the Intensive Care Unit in Abha, Saudi Arabia. Saudi Medical Journal, 24, 1374-1376. 